\title{
Criminality among Former Child and Adolescent Psychiatric Patients and Matched Controls
}

\author{
Anna-Karin Ivert', Mike Zyto², Hans Adler ${ }^{3}$, Marie Torstensson Levander'1, \\ Per Anders Rydelius ${ }^{2}$, Sten Levander ${ }^{1 *}$ \\ ${ }^{1}$ Department of Criminology, Malmö University, Malmö, Sweden \\ ${ }^{2}$ Karolinska Institute, Department of Women's and Children's Health, Astrid Lindgren Children's Hospital, Stockholm, Sweden \\ ${ }^{3}$ Department of Clinical Sciences, Psychiatry, Lund University, Lund, Sweden \\ Email: *stenlevander@gmail.com
}

How to cite this paper: Ivert, A.-K., Zyto, M., Adler, H., Levander, M.T., Rydelius, P.A. and Levander, S. (2017) Criminality among Former Child and Adolescent Psychiatric Patients and Matched Controls. Open Journal of Medical Psychology, 6, 16-30.

http://dx.doi.org/10.4236/ojmp.2017.61002

Received: September 23, 2016

Accepted: December 11, 2016

Published: December 14, 2016

Copyright $\odot 2017$ by authors and Scientific Research Publishing Inc. This work is licensed under the Creative Commons Attribution International License (CC BY 4.0).

http://creativecommons.org/licenses/by/4.0/

\begin{abstract}
Background: Externalizing symptoms in children (aggression, oppositionality, property and status violations), and the Attention Deficit Hyperactivity Disorder (ADHD) triad of problems (inattention, hyperactivity, impulsivity) display a substantial comorbidity. The "short temper" problem is common to these syndromes, which are predictive of a range of negative life outcomes including substance abuse and criminality in adulthood. There is a gender gap for the syndromes (boys are more affected), for criminality (men are more criminal) and knowledge (we know less about girls' criminal careers). Aims: The main aim was to compare crime rates and crime profiles among former Child and Adolescent Psychiatric (CAP) patients with corresponding data for matched controls, focusing externalizing and internalizing psychiatric symptoms, sex and adverse social factors. Method: Data for 6055 former CAP-Stockholm outpatients were extracted from available treatment registers. For each CAP patient, two matched controls from the general population were randomly selected from the same area of residence, of the same sex and with the same year of birth (N approx. 12,000). Data on criminality for these individuals were obtained from a Swedish police register which also includes crimes committed prior to age 15. Results: Overall, twice as many former CAP patients were registered for crimes at a mean age of 21.4 compared to the controls. The over-representation was larger for crimes of violence. Females were registered for a much lower number of crimes, particularly crimes of violence (gender gap). The gender gap among the CAP patients was smaller than among controls. Compared with controls, CAP patients characterized by externalizing problems at referral had an odds ratio (OR) for crimes of 5 for males and 10 for females. Neglect was the only adverse social factor which was associated with a higher crime rate and affected boys more than girls. Compared to previous Swedish CAP cohorts, the criminality of the current cohort was much higher. Conclusion: In-depth studies of female crime careers characterized by externalising problems are needed. Child psychiatric services must find new and more effective
\end{abstract}


ways of identifying and treating children with such problems, regardless of sex. The findings can guide the choice of strategies which will reduce crime rate.

\section{Keywords}

Child and Adolescent Psychiatry, Criminality, Longitudinal, Diagnoses, Externalizing, Internalizing, Neglect

\section{Background}

It appears to be possible to classify the onset of criminality and its subsequent development over the life-course into a small set of typical patterns. Moffitt's [1] two main patterns of criminal careers, the life-course-persistent pattern (LCP) and the adolescent-limited pattern $(A L)$ have now been verified in a large number of studies. The individuals who fit the LCP pattern have an early onset of antisocial behavior and a relatively stable level of criminal activity over the life-course. In contrast, the adolescentlimited pattern is characterized by a later age of onset and a concentration of criminality to the period of adolescence. Life-course-persistent offending is assumed to reflect the interaction between neuropsychiatric risk factors and a disadvantaged environment, as manifested in factors such as inadequate parenting, disrupted family bonds, poverty, and poor relations with peers and teachers [2] [3] [4]. It should be noted that two child psychiatric diagnoses characterized by externalizing symptoms share descriptive features with the LCP pattern: Attention Deficit Hyperactivity Disorder (ADHD) and Conduct Disorder (CD) [5]. Externalizing symptoms in childhood appear to belong to a higher order factor [5], are associated with a range of negative clinical outcomes in adulthood and tend to persist over the life course [6] [7].

With respect to psychiatric disorders in adulthood, some are associated with a moderate increase in criminality, such as psychotic illnesses, others with a substantial increase, particularly personality disorders with externalizing symptoms and comorbid substance abuse. Many of these disorders have precursors in childhood and adolescence [8] and are associated with a higher crime risk [9] [10] [11] [12]. To exemplify, a study of a representative sample of 1420 children aged 9,11 , and 13 who were then followed annually through age 16 for signs of psychiatric disorders showed that children with specific patterns of psychopathology (emotional as well as behavioral problems), and with and without $C D$, were at increased risk of later criminality [6]. A Swedish followup study of 1400 Child and Adolescence psychiatric (CAP) patients treated between 1975 and 1990 and followed until the end of 2003 illustrates the substantially higher risk of future criminality in this group: every second male and every fifth female patient had been registered for crime [13]. This is a higher percentage than the national average (28\% and $6 \%$ of the male and female population, percentages based on National Swedish Statistics).

Still worse outcomes were obtained in a cohort of 80 delinquent boys, admitted at an average age of 14 and treated between 1975 and 1980 at Lövsta, the Swedish "borstal school" specializing in psychiatric services for boys with an early onset of criminality. 
All were diagnosed with CD (DSMIII) and 70\% with ADHD. Prepsychotic features (such as "cognitive slippage") were common. At follow-up (age 30), 13\% were dead, all by non-natural causes, and $9 \%$ had been diagnosed with schizophrenia. They had also been convicted of 12,000 offences including 700 crimes of violence. Only $8 \%$ (six boys) had attained a reasonable level of social adjustment [14].

The issue whether childhood diagnoses/syndromes or specific symptoms/problems are the best predictors of future criminality is studied among former Norwegian CAP in-patients [15]. The authors also looked into how many adverse contextual factors added to the predictions, separately and by interaction with psychiatric problems. ADHD symptoms were not specifically predictive of future criminality, in contrast to CD ones. CD symptoms interacted with the ADHD symptom of hyperactivity, producing still higher Relative Risk (RR) coefficients.

In a population-based study of Kindergarten children followed over more than 20 years [16], hyperactivity, inattention, and physical aggression were assessed annually between the ages of 6 and 12 years. Childhood hyperactivity was highly predictive for later criminality in a univariate analysis, but not when covariates were introduced. In contrast high physical aggression was strongly predictive regardless of interaction effects. Inattention was not predictive of later criminality.

Boys/men commit crimes much more often than girls/women (the gender gap)consequently studies of crime tend to focus boys/men. We know less about girls/ women's criminality and their pathways into crime [17] [18]. Externalizing symptoms are strong predictors of life-time criminality and are much more common among boys (another gender gap). We do not have enough knowledge concerning the interaction between sexes and externalizing symptoms for long-term outcome, not even with respect to correlative knowledge. If we want more than that, i.e. to identify the major generative mechanisms behind the correlations, then we need more time-series data for girls and boys with respect to relevant issues [19] [20]. Furthermore, as gender roles are changing rapidly we should expect sex-linked period effects over time.

Summing up, the literature is not fully consistent, particularly with respect to recent vs older studies. There are period as well as geographical effects reflecting differences in how the problem of youth criminality is viewed and handled. The sampling problem (how much of the ice-berg is included) must play a role: the 80 most problematic boys of Sweden [14], CAP inpatients [15], or Kindergarten children [16]. Is there a threshold of symptom intensity which has to be passed before symptoms like childhood impulsivity and hyperactivity start to matter for later criminality? What is the impact of adverse social factors as main effects and within which range do neuropsychiatric problems interact with such adverse social factors?

\subsection{The Current Study}

The present study analyses a set of broad issues relating to criminality and psychiatric problems. The Stockholm County Council's Clinical Department for Child and Adolescent Psychiatry has collected relevant data in a structured manner over a period of more than 20 years and for more than 100,000 patients. By sampling from among these patients, it is possible to compile large data sets for the study of specific research issues. 


\subsection{Aims of the Study}

The study has three specific aims: Firstly, to compare crime rates and crime profiles among former CAP patients with corresponding data for matched controls. Secondly, to link the crime data relating to former CAP patients to the types of problems that motivated their contacts with child psychiatric services, to sex and to adverse social background factors. Thirdly, by comparing the current CAP data with previous Swedish data we wanted to study two types of period effects-whether CAP patients of today are registered for crime more often than previously, and whether the "gender gap" has changed over time.

\section{Method}

\subsection{Study Population and Data}

The Stockholm County Council's Clinical Department for Child and Adolescent Psychiatry offers in- and outpatient services to children and adolescents up to age 18 within a catchment area of 1.5 million inhabitants. A computerised system is used for patient statistics (PASTILL) based on information collected for each child who visits any of the clinics. The clinician (child psychiatrist, psychologist or social worker) fills out a form with information on variables such as cause of referral and referral source, symptoms, diagnoses (according to DSM-IV), psychosocial stressors, length and type of treatment, residential neighborhood, and social background [21]. This form is similar to the original MacFarlane form from the 1930s [22] which has since been used in a large number of studies. The criteria used to describe behavioral symptoms in children are similar to the criteria from DSM-IV-TR.The data set, which also includes additional information from other sources, such as the crime register, allows for analyses of the kind described above, i.e., longitudinal analyses utilising information on individual, family and contextual variables on several levels.

For this article, CAP patients were sampled from the complete PASTILL database according to the following inclusion criteria: born 1989 or earlier, having finished their contacts with the clinic in 2003-2005, having had outpatient contacts, and being younger than age 26 at inclusion in the database. With these constraints, this database consists of 3734 female and 2321 male former outpatients. The database includes information on, e.g., social background, residential data, family context, psychosocial stressors, symptoms, diagnoses, GAF ratings and treatment. In this study, a subset of variables was analyzed based on constraints that missing values should be rare and the information judged to be sufficiently robust.

For each included CAP patient, two same-sex controls were randomly selected from the population register from among children living in the same local neighborhood and who were born in the same year: 7468 females and 4642 males. In this way we aimed to control for effects of local contextual factors associated with different areas of residence. For a few CAP patients, only one control could be found within the residential area. As a result of the matching procedure, the controls do not represent a truly random sample of all individuals born in the years specified above and living in Stockholm. In the analyses the two control groups were combined (there were no significant differences between the two groups for any comparison). 


\subsection{Clinical Characterization of the CAP Patients}

During more than one hundred years a majority of the childhood psychiatric symptoms have been conceptualized as belonging to two higher-order factors: internalizing and externalizing ones (autoplastic and alloplastic in older terminology). This conceptualization has been repeatedly verified, also recently as part of the DSM-5 project [2] [5]. In line with this we classified our subjects to form four groups for the two sexes: neither internalizing nor externalizing problems (Group 0); internalizing but not externalizing problems (Group 1); externalizing but not internalizing problems (Group 2); and combined internalizing and externalizing problems (Group 3). Typical internalizing problems described and assessed in the CAP database are symptoms of fear, anxiety, compulsion and depression. Typical externalizing problems are defiance, aggression, acting out, hyperactivity and age-inappropriate behavior including substance use/abuse. The description of referral reasons and the associated actual problems appeared to have been coded much more robustly than diagnoses, and for many outpatients there were no diagnoses available. The validity of the classification conducted on the basis of the reasons for referral was checked by computing correlations with specific problems (vide supra), as well as more advanced analyses (intra-class correlation coefficients, cluster analyses). These data checking procedures are not reported here but were consistent with theoretical as well as empirical expectations.

\subsection{Data on Criminality}

Individual crime data were collected from the National Crime Register (NCR) administered by the National Council for Crime Prevention. The register contains annual information on offences reported to the police from age 15 (the age of criminal responsibility in Sweden). However, under-age persons may also be recorded by the police if suspected of crime. Thus, subjects who committed offences very early can be identified (actually from age 8 , and with reliable data from age 13 ). The NCR register also contains information on whether the person was prosecuted for an offence and convicted, if older than 15.

The NCR register lists offences according to the Swedish Penal Code. The number of different offences listed was overwhelmingly large and a courser categorization of the offences, and their seriousness, was required. The offences were classified into eight main categories (based on Chapters of the Swedish Penal Code): Serious violence, Violence, Property crime, Fraud, Drug crime, Traffic violations, Drink driving and other offences. Criminality was registered separately for consecutive years making it possible to determine the age at onset of criminality, cumulative offending and criminal versatility during the teenage years. For each entry, the number of offences per age interval was coded as $0,1,2-4$ and $>4$ crimes.

\subsection{Analytical Strategy and Statistical Methods}

The CAP material represents a population rather than a sample. Hence, tests of statistical significance are meaningless with respect to many differences within the group, e.g., the fact that there are more females than males in the total material and relatively more males than females who display externalizing problems. Statistical significance 
constitutes a means of specifying the risk that a certain finding has been produced by chance, and this risk is negatively related to the sample size. In contrast, clinical significance relates to effect size as defined by Cohen, the d statistic [23] which is independent of sample size. In studies like the present one ( $N$ approximately 18,000), a large number of statistically significant results will be obtained (cf. the Project Metropolitan dataset of 15,117 children [24]). Most of these are trivial because the corresponding clinical significance (effect size, Cohen's d) will be much lower than 0.2 . Only clinically significant results are therefore reported, and almost all of these are highly significant $(p<0.001)$. For the same reason, the confidence intervals of the Odds Ratio (OR) coefficients are not reported because the size of these intervals is typically smaller than 0.05 for clinically significant effects for the current number of subjects. We do not elaborate on statistical $\mathrm{p}$ values beyond the four standard values: $<0.10,<0.05,<0.01$ and $<0.001$, in line with classical inference theory. We never specify more than three significant digits (which may represent 1000 unique values) in order to avoid pseudo-precision. We have kept our statistical analyses rather basic, and have restricted ourselves to the use of standard methods. The calculations were conducted using the SPSS package.

\subsection{Ethics}

The study was approved by the Regional Ethics Committee in Stockholm. The PSC records were linked to the CAP patient records via a single key, after which the complete database was anonymized in line with the recommendations of the ethics committee.

\section{Results}

\subsection{Cause of Referrals}

For most of the patients (around 90\%), at least one classifiable reason for their contacts with CAP clinics was available, as well as information on the referring agent (family, school, social services officers, police [21]). For almost all patients, there were also data on which types of problems had been identified. The reasons for referral and the number of males and females in each referral category are presented in Table 1 . The percentages do not sum to 100 because of the many cases involving multiple reasons for referral. For females, one or two reasons for referral were listed for $69 \%$ of the patients; the corresponding proportion for males was $63 \%$. Thus, around $30 \%$ of the females and $35 \%$ of the males had more than two listed reasons for referral.

As can be seen in Table 1, females had proportionately more internalizing than externalizing problems, and less often had school-related and neuro-developmental problems than males.

There was a significant difference with respect to sex-an over-representation of males in Groups 0 (neither internalizing nor externalizing problems) and 2 (externalizing problems), and an over-representation of females among those with internalizing problems $\left(\chi^{2}(3)=226, p<0.001\right)$. In Table 2 , the internalizing/externalizing subdivision is cross-tabulated with the other problems (parental; relational; school/leisure; neglect/stressors; neuropsychiatric-developmental) for the two sexes, expressed as percentages and analyzed by means of $\chi^{2}$ tests $(\mathrm{df}=3)$. All problems, with the exception of 
Table 1. Reasons for the CAP contact (more than one may be listed) assessed at the time of the contact, and number (percent) of girls/boys in each category

\begin{tabular}{ccc}
\hline \multirow{2}{*}{ Reason for the CAP contact } & \multicolumn{2}{c}{ \# of patients } \\
\cline { 2 - 3 } No contact reason & Girls $(\mathrm{n}=3734)$ & Boys (n = 2321) \\
Internalizing problems & $474(13 \%)$ & $272(12 \%)$ \\
Externalizing problems & $3230(87 \%)$ & $1460(63 \%)$ \\
Parental problems & $972(26 \%)$ & $850(37 \%)$ \\
Relation problems within the family & $1307(35 \%)$ & $883(38 \%)$ \\
Problems at school/leisure time & $1024(27 \%)$ & $455(20 \%)$ \\
Exposure to neglect/stressors & $600(16 \%)$ & $619(27 \%)$ \\
Neuropsychiatric developmental problems & $595(16 \%)$ & $275(12 \%)$ \\
Other problems & $215(5.8 \%)$ & $437(19 \%)$ \\
\hline
\end{tabular}

Table 2. Percentages of various problems in former CAP patients subdivided into four subgroups based on contact reason: neither internalizing, nor externalizing (None); Internalizing; Externalizing; and Both internalizing and externalizing. Data are given for boys and girls separately. Statistical significance was computed as $\chi^{2}$ coefficients $(\mathrm{df}=3)$. ${ }^{* *}: p<0.001 ;{ }^{*}: p<0.05$. NS: Not Significant.

\begin{tabular}{|c|c|c|c|c|c|c|c|c|c|c|}
\hline \multirow{2}{*}{ Intern./Extern. } & \multicolumn{5}{|c|}{ Girls } & \multicolumn{5}{|c|}{ Boys } \\
\hline & None & Int & Ext & Both & $\chi^{2}$ & None & Int & Ext & Both & $\chi^{2}$ \\
\hline Parental problems & 17 & 22 & 53 & 55 & $448^{\star * *}$ & 21 & 25 & 50 & 51 & $191^{* * *}$ \\
\hline $\begin{array}{l}\text { Relational problems } \\
\text { within the family }\end{array}$ & 18 & 19 & 28 & 34 & $80^{\star * \star}$ & 12 & 14 & 21 & 30 & $70^{*}$ \\
\hline $\begin{array}{c}\text { Problems at } \\
\text { school/leisure time }\end{array}$ & 8 & 10 & 22 & 28 & $188^{* * *}$ & 16 & 18 & 33 & 36 & $103^{\star * *}$ \\
\hline $\begin{array}{c}\text { Exposure to } \\
\text { neglect/stressors }\end{array}$ & 16 & 10 & 10 & 17 & $43 \mathrm{NS}$ & 10 & 10 & 7 & 13 & $9 \mathrm{NS}$ \\
\hline $\begin{array}{c}\text { Neuropsychiatric } \\
\text { developmental problems }\end{array}$ & 4 & 3 & 10 & 9 & $75^{\star * *}$ & 17 & 10 & 20 & 25 & $58^{* * *}$ \\
\hline
\end{tabular}

neglect, were much more common in Groups 2 and 3 (externalizing problems), with this pattern being similar for both sexes.

\subsection{Crime Profiles}

Age at the time of the subjects' first entry in the crime register was similar for former CAP patients and controls; 14.9 vs. 15.3 for males (SD approx. 2.05) and 15.1 vs. 15.3 for females (SD approx. 1.98). The difference is less than 0.2 SD for both sexes-and even if statistically significant (very large $\mathrm{N}$ ), it is clinically trivial. Thus, onset of criminality was similar for boys and girls regardless of whether they were former CAP patients or controls. 
Overall, former CAP patients were registered for at least twice as many offences as the controls. For females, the CAP over-representation was non-significant for two offence categories: Traffic offences and Drink driving. CAP males were more criminal than control males for all offences.

In the following, we based the crime analyses on eight offence categories rather than on specific offences of which some were unusual and difficult to classify. Among the former CAP males, $38 \%$ had at least one entry in the crime register vs. $22 \%$ for control males. The corresponding percentages for females were $24 \%$ and $13 \%$. The criminality of the patients and the controls for the various offence categories and for the two sexes is presented in Table 3. The crime rate is expressed as the number of offences per 1000 subjects. Odds Ratios (ORs) can be computed as the ratio between adjacent columns, for example (for females, one crime and serious violence) $17 / 4.8=3.54$, but are not presented in the table.

The results confirm previous research on female crime patterns. Their criminality is less frequent and less violent, particularly in relation to serious violence, by comparison with males. The focus of female crime is directed at property offences and fraud. The crime rates are, in general, higher among CAP-females (and males) by comparison with controls, particularly for violence and serious violence.

\subsection{Criminality of Former CAP Patients in Relation to Cause of Referral}

In the next step we analyzed the criminality (number of offences) of CAP patients for a subset of specific and common offences (rather than the eight crime categories) in order to attain as much specificity/homogeneity as possible. Subjects were subdivided by sex and the groups based on the externalizing vs. internalizing causes of referral (Groups 0, 1, 2 and 3). The results are presented in Table 4. Criminality is presented both in terms of numbers of offences and expressed as Odds Ratio (OR) scores relative to controls. The differences were analyzed using 2-way ANOVAs (sex and group), with the subjects' age at the date of the output from the crime register as a covariate (using this covariate, crime was analyzed at age 21.4 for all subjects). Most females had been referred as a result of internalizing problems. These females had ORs larger than 1 for all offences except car theft. Males with internalizing problems, on the other hand, had ORs smaller than 1, i.e. were less prone to criminality than their controls, except in relation to serious vandalism and drug crimes. Patients who were referred as a result of externalizing problems had the highest criminality rate for almost all offences, and the difference between the sexes was smaller. Thus externalizing problems were associated with a substantial and highly significant increase in the OR for most of the crimes and with a smaller sex ratio. The CAP females' ORs were typically twice as large as the ORs of the males. There were no salient differences between Groups 2 and 3; i.e. having internalizing as well as externalizing problems did not change the criminal propensity. Group 0 (neither internalizing nor externalizing problems) displayed a moderately increased criminal propensity-larger than that of those with internalizing problems and substantially smaller than that of those with externalizing problems (Groups 2 and 3). The ORs suggest that the gender gap is smaller among CAP patients than among controls. 
Table 3. Crime rate per 1000 persons among controls and former CAP patients, for seven crime categories, multiple crimes $(1=$ registered for one crime, $2=$ two to three, $3=$ four or more crimes), and the two sexes. $\chi^{2}$ values refer to the comparison between controls and CAP patients, within the two sexes, and with $\mathrm{df}=6$ (four levels of crime, including 0 ).

\begin{tabular}{|c|c|c|c|c|}
\hline \multirow{2}{*}{ Crime category } & \multicolumn{2}{|c|}{ Girls } & \multicolumn{2}{|c|}{ Boys } \\
\hline & CAP & Controls & CAP & Controls \\
\hline \multicolumn{5}{|l|}{ Serious violence } \\
\hline 1 & 17.0 & 4.8 & 68.6 & 24.2 \\
\hline 2 & 4.5 & 0.8 & 36.5 & 12.9 \\
\hline 3 & 0.8 & 0.0 & 9.2 & 4.1 \\
\hline$\chi^{2}$ & \multicolumn{2}{|c|}{$82.3^{* * *}$} & \multicolumn{2}{|c|}{$131^{\star * *}$} \\
\hline \multicolumn{5}{|l|}{ Violence } \\
\hline 1 & 34.9 & 14.4 & 103.8 & 51.7 \\
\hline 2 & 25.9 & 6.8 & 92.6 & 28.9 \\
\hline 3 & 5.1 & 1.9 & 47.0 & 21.0 \\
\hline$\chi^{2}$ & \multicolumn{2}{|c|}{$151^{\star * *}$} & \multicolumn{2}{|c|}{$192^{* * *}$} \\
\hline \multicolumn{5}{|l|}{ Property crimes } \\
\hline 1 & 136.1 & 79.1 & 119.7 & 75.3 \\
\hline 2 & 44.2 & 17.1 & 77.9 & 21.6 \\
\hline 3 & 4.7 & 3.3 & 25.5 & 12.8 \\
\hline$\chi^{2}$ & \multicolumn{2}{|c|}{$156^{* * *}$} & \multicolumn{2}{|c|}{$155^{* * *}$} \\
\hline \multicolumn{5}{|l|}{ Fraud/Economic } \\
\hline 1 & 19.1 & 10.0 & 46.9 & 21.7 \\
\hline 2 & 2.8 & 1.3 & 16.9 & 7.6 \\
\hline 3 & 0.2 & 0.4 & 3.5 & 0.9 \\
\hline$\chi^{2}$ & \multicolumn{2}{|c|}{$31.5^{\star * *}$} & \multicolumn{2}{|c|}{$56.1^{* * *}$} \\
\hline \multicolumn{5}{|l|}{ Traffic crimes } \\
\hline 1 & 4.4 & 2.1 & 35.7 & 25.7 \\
\hline 2 & 0.6 & 0.4 & 16.0 & 7.3 \\
\hline 3 & 0.0 & 0.0 & 4.9 & 3.5 \\
\hline$x^{2}$ & \multicolumn{2}{|c|}{$2.6 \mathrm{NS}$} & \multicolumn{2}{|c|}{$19.9^{* *}$} \\
\hline \multicolumn{5}{|l|}{ Drunk driving } \\
\hline 1 & 1.9 & 1.5 & 14.3 & 6.7 \\
\hline 2 & 0.0 & 0.1 & 1.5 & 1.6 \\
\hline$\chi^{2}$ & \multicolumn{2}{|c|}{$2.6 \mathrm{NS}$} & \multicolumn{2}{|c|}{$12.3^{*}$} \\
\hline \multicolumn{5}{|l|}{ Drug crimes } \\
\hline 1 & 18.8 & 6.0 & 40.6 & 24.6 \\
\hline 2 & 10.5 & 3.2 & 35.9 & 10.9 \\
\hline 3 & 1.1 & 0.7 & 19.7 & 8.3 \\
\hline$\chi^{2}$ & \multicolumn{2}{|c|}{$79.1^{* * *}$} & \multicolumn{2}{|c|}{$85.1^{* * *}$} \\
\hline \multicolumn{5}{|l|}{ Other } \\
\hline 1 & 50.8 & 25.0 & 119.7 & 65.4 \\
\hline 2 & 14.4 & 5.0 & 95.5 & 28.6 \\
\hline 3 & 0.9 & 0.6 & 30.9 & 11.3 \\
\hline$\chi^{2}$ & \multicolumn{2}{|c|}{$92.8^{* * *}$} & & \\
\hline
\end{tabular}


Table 4. Frequency of crimes for a subset of crimes, for four groups of former CAP patients based on referral cause and subdivided by sex; and OR in comparison with matched controls.

\begin{tabular}{|c|c|c|c|c|c|c|c|c|c|c|c|}
\hline \multirow{2}{*}{$\begin{array}{l}\text { Internalizing/ } \\
\text { Externalizing }\end{array}$} & \multicolumn{2}{|c|}{ None } & \multicolumn{2}{|c|}{ Internalizing } & \multicolumn{2}{|c|}{ Externalizing } & \multicolumn{2}{|c|}{ Both } & \multirow{2}{*}{ Group } & \multirow{2}{*}{ Sex } & \multirow{2}{*}{ Interact } \\
\hline & Boys & Girls & Boys & Girls & Boys & Girls & Boys & Girls & & & \\
\hline \multicolumn{12}{|l|}{ Serious assault } \\
\hline Freq. & 0.05 & 0.00 & 0.01 & 0.00 & 0.06 & 0.01 & 0.05 & 0.01 & & & \\
\hline OR & 3.1 & 0.1 & 0.5 & 1.2 & 4.2 & 15.7 & 3.4 & 10.9 & $13.9^{* * *}$ & $61.6^{* * *}$ & $8.7^{\star * *}$ \\
\hline \multicolumn{12}{|l|}{ Assault } \\
\hline Freq. & 0.25 & 0.07 & 0.11 & 0.04 & 0.56 & 0.26 & 0.52 & 0.16 & & & \\
\hline OR & 2.1 & 2.8 & 0.9 & 1.4 & 4.6 & 10.4 & 4.3 & 6.5 & $87.4^{* * *}$ & $165.7^{* * *}$ & $15.6^{* * *}$ \\
\hline \multicolumn{12}{|l|}{ Robbery } \\
\hline Freq. & 0.08 & 0.00 & 0.03 & 0.00 & 0.18 & 0.02 & 0.19 & 0.02 & & & \\
\hline OR & 1.9 & 1.3 & 0.6 & 1.3 & 4.2 & 9.6 & 4.3 & 10.5 & $20.1^{* * *}$ & $96.9^{\star * *}$ & $12.4^{\star * \star}$ \\
\hline \multicolumn{12}{|l|}{ Burglary } \\
\hline Freq. & 0.27 & 0.20 & 0.11 & 0.16 & 0.59 & 0.47 & 0.47 & 0.33 & & & \\
\hline OR & 2.1 & 1.7 & 0.9 & 1.4 & 4.5 & 4.0 & 3.6 & 2.8 & $69.1^{* * *}$ & $10.3^{\star * *}$ & $5.6^{\star * *}$ \\
\hline \multicolumn{12}{|l|}{ Car theft } \\
\hline Freq. & 0.06 & 0.00 & 0.02 & 0.00 & 0.19 & 0.02 & 0.12 & 0.02 & & & \\
\hline OR & 1.8 & 1.0 & 0.7 & 0.3 & 6.0 & 6.7 & 3.9 & 8.0 & $29.5^{* * *}$ & $112.5^{\star * *}$ & $16.8^{\star * *}$ \\
\hline \multicolumn{12}{|c|}{ Serious Vandalism } \\
\hline Freq. & 0.14 & 0.01 & 0.07 & 0.01 & 0.33 & 0.07 & 0.40 & 0.05 & & & \\
\hline OR & 2.9 & 2.4 & 1.5 & 1.2 & 6.9 & 11.0 & 8.3 & 7.6 & $32.3^{* * *}$ & $150.2^{\star * *}$ & $17.4^{\star * *}$ \\
\hline \multicolumn{12}{|c|}{ Violence against staff } \\
\hline Freq. & 0.10 & 0.01 & 0.05 & 0.01 & 0.24 & 0.06 & 0.19 & 0.07 & & & \\
\hline OR & 2.1 & 2.3 & 1.0 & 2.5 & 5.0 & 12.0 & 3.9 & 13.7 & $28.9^{* * *}$ & $88.8^{\star * *}$ & $8.7^{\star * *}$ \\
\hline \multicolumn{12}{|l|}{ Drug crimes } \\
\hline Freq. & 0.26 & 0.05 & 0.12 & 0.02 & 0.45 & 0.10 & 0.40 & 0.10 & & & \\
\hline OR & 2.7 & 3.0 & 1.2 & 1.3 & 4.6 & 5.4 & 4.0 & 5.7 & $24.3^{* * *}$ & $128.6^{* * *}$ & $8.9^{* * *}$ \\
\hline
\end{tabular}

\subsection{Contextual and Relational Problems and Crime among Former CAP Patients}

The contextual and relational problems listed in Table 2 (family, relational, neuro-developmental etc. problems) were analyzed as possible modulators of criminality (specific crimes), while retaining controls for sex and the reason for referral. In order to avoid the mass significance problem associated with a large number of separate analyses, only main effects reaching $p<0.01$ and interaction effects reaching $p<0.001$ were interpreted. The outcome of the analyses was fairly clear-cut. There were no effects of the first three contextual problems, i.e. parental, relational and school/leisure problems. For the developmental problems there was an isolated main effect $(\mathrm{F}(1)=15.1, p<$ 0.001 ) on assault with no interaction effects and an associated OR close to 2. Neglect 
increased the criminal propensity for more than half of the types of crimes (main effect), for some offences with a sex interaction suggesting that neglect increased criminality more in males than in females. Main effects $(p<0.001)$ were obtained for assault, burglary (with a sex interaction), car theft (with a sex interaction), violence against staff/public servants, and drug offences (with a sex interaction). The ORs of the significant main effects ranged between 1.3 and 2.0.

\section{Discussion}

A higher number of former CAP patients than controls had entries in the crime register, in line with our main hypothesis. This difference was more pronounced for females: they had a substantially higher number of offences than controls in almost all crime categories, with males displaying a similar but less pronounced pattern. Among the controls, males were registered for far more offences in all crime categories except property crime and to some extent fraud/economic offences, in line with the gender gap observation. It might be noted that the gender gap was less pronounced in the CAP vs the control subjects. Among former CAP patients, reasons for referral suggestive of externalizing problems were associated with a substantially higher level of criminality as estimated by the number of persons with entries in the crime register as well as the number of specific offences, and this effect was more pronounced among the females. The highest Odds Ratios (OR) relative to controls (>12) were obtained for females with externalizing problems and for violent offences, i.e. serious assault and violence against staff/public servants. The combination of externalizing and internalizing problems was common, but criminality appeared to be almost exclusively linked with the externalizing problems, with no difference between the sexes. Hence, we could not replicate the finding reported by Hodgins and co-workers [25] that males with combined problems displayed a higher severity of externalizing problems and potentially more antisocial activities.

Age at the first registered crime did not differ much between former CAP patients and matched controls. There was no contribution from the majority of the contextual or relational factors that could explain the differences in criminal propensity among the patients, with one exception. Exposure to neglect was strongly and systematically associated with increased criminality for a majority of the crimes, particularly among the males. Finally, developmental problems, which were much more common among males, were significantly associated with assault.

Our main findings replicate many of the findings reported by Lee $\mathrm{N}$ Robins in her ground-breaking book 50 years ago [26] and are in line with the differential effects of various child psychiatric diagnoses for criminality in adulthood as demonstrated by Copeland and colleagues [6]. The latter noted that after controlling for a range of confounding factors, $15 \%$ of the variance of criminality in young adulthood could be attributed to a child psychiatric disorder among males, and $20 \%$ among females. The strongest contribution from a single diagnosis was found for Conduct Disorder (CD), which only rarely appeared without other co-morbid diagnoses and problems. Similar findings were obtained in a twin study of childhood hyperactivity and conduct problems as potential predictors of Antisocial Personality Disorder and crime in adulthood [7] and in a Norwegian longitudinal study of former CAP patients [27]. 
In our study, former CAP patients with internalizing but not externalizing problems did not differ from controls and displayed a trend towards an inverse sex difference, males being less criminal than females. In contrast, for former patients with externalizing problems, the increase in criminality was substantial (ORs for males were typically around 5; for females twice as large). It should be noted that this category of CAP patients also had a much higher load of other problems at referral: parental, relational, school/leisure time and neuro-developmental problems. However, these contextual factors did not explain much of the variation in the material as a whole, with one exception: neglect. It is not very likely that a specific contextual factor increases the risk of criminality in a linear way. Some of the inconsistencies found in the literature appear to reflect the criminality outcome being modulated via non-linear interaction effects involving many factors. This has been illustrated in a study of maltreatment in childhood and cumulative criminal convictions from age 12 to 24 . Overall there were few significant associations, and those which were significant represented specific combinations of a number of factors [28]. Being exposed to neglect was not in itself associated with later criminality.

In the Stockholm CAP-cohort of the 1950s, only 3\% of the females were later registered for criminality [29] compared with the $14 \%$ who had already been registered for crime at age 21 in our own material. There appears to be a secular trend of increasing criminality among today's former female CAP patients by comparison with earlier cohorts [30]. The reasons for this increase should be further explored and, most importantly, studied in terms of the interaction between societal, situational and individual factors using multi-level statistical tools [19].

\section{Strengths and Limitations}

Sweden has a long tradition of longitudinal CAP studies and high-quality national registers. The study is based on a comparatively large sample of former CAP outpatients, and matched controls, using data collection forms that are similar to those used in previous Swedish studies. The design, and particularly the matching procedure, may be assumed to minimize the effect on crime propensities of the social conditions in residential areas. This should not be construed as an assumption that social factors are not significant in relation to criminality in the form of main or interaction effects. It is a strength that detailed records of criminality were available in a national register, and included data relating to under-aged perpetrators, albeit not reliable for subjects younger than age 13 .

The PASTILL database has evolved over a long period of time. The assessments appear to have become more stringent with time. However, most of the outpatients had not received a diagnosis, and in the early years of the database, the diagnoses of those who also had a history as inpatients did not meet DSM-IV criteria-based standards. This was the reason for restricting our analyses to outpatients. The use of the reasons for referral appeared to be the most robust way of creating a rough categorization of the patients, resulting in a $2 * 2$ matrix based on the presence of internalizing and externalizing features. The weakness of this procedure and the resulting measurement noise is compensated for by the force of a large $\mathrm{N}$. 


\section{Conclusion}

Crime onset (register data) was similar for males/females and CAP patients/controls. Former CAP patients were registered for twice as many crimes as controls at a mean age of 21.4 years. Females, both CAP patients and controls, were much less often registered for crimes compared to males, particularly for crimes of violence. The large sex differences in criminality among the controls were less pronounced among the CAP patients (smaller gender gap). CAP females with externalizing problems were registered for ten times as many crimes as their controls, and this difference was also substantially larger for crimes of violence. CAP males with externalizing problems were registered for five times as many crimes as their controls, and this difference was also larger for crimes of violence. CAP females with isolated internalizing problems were registered for more crimes than their controls while the corresponding category of males was registered for fewer crimes. Neglect, in contrast to other adverse social factors, is an independent contributor to high crime rates, particularly for males. There appears to be a period effect, suggesting that CAP treatment of patients with externalizing problems was more successful in preventing criminality previously than it is today-we need to develop a better understanding of why and address how such patients should be identified, referred, assessed and treated by the CAP services. Identifying generative mechanisms leading to crime, and providing appropriate interventions at critical points in the causal chain should reduce crime in a life-course perspective. Our findings help us to narrow the search for generative mechanisms.

\section{References}

[1] Moffitt, T.E. (1993) Adolescence-Limited and Life-Course-Persistent Antisocial Behavior: A Developmental Taxonomy. Psychological Review, 100, 674-701. https://doi.org/10.1037/0033-295X.100.4.674

[2] Westen, D., DeFife, J.A., Malone, J.C. and DiLallo, J. (2014) An empirically Derived Classification of Adolescent Personality Disorders. Journal of the American Academy of Child and Adolescent Psychiatry, 53, 528-549. https://doi.org/10.1016/j.jaac.2013.12.030

[3] Piquero, A.R. and Moffitt, T.E. (2005) Explaining the Facts of Crime: How the Developmental Taxonomy Replies to Farrington's Invitation. In: Farrington, D.P., Ed., Integrated Developmental and Life-Course Theories of Offending, Advances in Criminological Theory, Transaction Publishers, New Brunswick, NJ, 51-72.

[4] Piquero, A.R., Farrington, D.P. and Blumstein, A. (2003) The Criminal Career Paradigm. Crime and Justice: A Review of Research, 30, 359-506. https://doi.org/10.1086/652234

[5] Reef, J., Diamantopoulou, S., van Meurs, I., Verhulst, F.C. and van der Ende, J. (2011) Developmental Trajectories of Child to Adolescent Externalizing Behavior and Adult DSM-IV Disorder: Results of a 24-Year Longitudinal Study. Social Psychiatry and Psychiatric Epidemiology, 46, 1233-1241. https://doi.org/10.1007/s00127-010-0297-9

[6] Copeland, W.E., Miller-Johnson, S., Keeler, G., Angold, A. and Costello, E.J. (2007) Childhood Psychiatric Disorders and Young Adult Crime: A Prospective, Population-Based Study. American Journal of Psychiatry, 164, 1668-1675. https://doi.org/10.1176/appi.ajp.2007.06122026

[7] Simonoff, E., Elander, J., Holmshaw, J., Pickles, A., Murray, R. and Rutter, M. (2004) Predictors of Antisocial Personality. Continuities from Childhood to Adult Life. British Journal of Psychiatry, 184, 118-127. https://doi.org/10.1192/bjp.184.2.118 
[8] Dalteg, A., Zandelin, A., Tuninger, E. and Levander, S. (2014) Psychosis in Adulthood Is Associated with High Rates of ADHD and CD Problems during Childhood. Nordic Journal of Psychiatry, 68, 560-566. https://doi.org/10.3109/08039488.2014.892151

[9] Farrington, D.P. (1999) Conduct Disorder and Delinquency. In: Steinhausen, H.C. and Verhulst, F.C., Eds., Risks and Outcomes in Developmental Psychopathology, Oxford University Press, New York, 165-192.

[10] Farrington, D.P. (2005) Introduction to Integrated Developmental and Life-Course Theories of Offending. In: Farrington, D.P., Ed., Integrated Developmental and Life-Course Theories of Offending, Advances in Criminological Theory, Transaction Publishers, New Brunswick, NJ, 1-14.

[11] Abram, K.M., Teplin, L.A., McClelland, G.M. and Dulcan, M.K. (2003) Comorbid Psychiatric Disorders in Youth in Juvenile Detention. Archives of General Psychiatry, 60, 10971108. https://doi.org/10.1001/archpsyc.60.11.1097

[12] Loeber, R., Farrington, D.P., Stouthamer-Loeber, M. and Van Kammen, W.B. (1998) Multiple Risk Factors for Multiproblem Boys: Co-Occurrence of Delinquency, Substance Use, Attention Deficit, Conduct Problems, Physical Aggression, Covert Behavior, Depressed Mood, and Shy/Withdrawn Behavior. In: Jessor, R., Ed., New Perspectives on Adolescent Risk Behavior, Cambridge University Press, New York, 91-149. https://doi.org/10.1017/CBO9780511571138.005

[13] Engqvist, U. and Rydelius, P.-A. (2007) Child and Adolescent Psychiatric Patients and Later Criminality. BMC Public Health, 7, 221-229. https://doi.org/10.1186/1471-2458-7-221

[14] Dalteg, A. and Levander, S. (1998) 12000 Crimes by 75 Boys. Journal of Forensic Psychiatry, 9, 39-57. https://doi.org/10.1080/09585189808402178

[15] Mordre, M., Groholt, B., Kjelsberg, E., Sandstad, B. and Myhre, A.M. (2011) The Impact of ADHD and Conduct Disorder in Childhood on Adult Delinquency: A 30 Years Follow-Up Study Using Official Crime Records. BMC Psychiatry, 11, 57. https://doi.org/10.1186/1471-244X-11-57

[16] Pingault, J.B., Côté, S.M., Lacourse, E., Galéra, C., Vitaro, F. and Tremblay, R.E. (2013) Childhood Hyperactivity, Physical Aggression and Criminality: A 19-Year Prospective Population-Based Study. PLoS ONE, 8, e62594. https://doi.org/10.1371/journal.pone.0062594

[17] Andersson, F., Levander, S. and Levande, M.T. (2013) A Life-Course Perspective on Girls' Criminality. In: Andershed, A.-K., Ed., Girls at Risk. Swedish Longitudinal Research on Adjustment Series, Springer, New York, 119-137.

[18] Kjelsberg, E. and Friestad, C. (2009) Exploring Gender Issues in the Development from Conduct Disorder in Adolescence to Criminal Behaviour in Adulthood. International Journal of Law and Psychiatry, 32, 18-22. https://doi.org/10.1016/j.ijlp.2008.11.004

[19] Wikström, P.-O., Oberwittler, D., Treiber, K. and Hardie, B. (2012) Breaking Rules: The Social and Situational Dynamics of Young People's Urban Crime. Oxford University Press, Oxford.

[20] Wikström, P.-O. (2011) Does Everything Matter? Addressing the Problem of Causation and Explanation in the Study of Crime. In: McGloin, J.M., Sullivan, C.J. and Kennedy, L.W., Eds., When Crime Appears. The Role of Emergence, Routledge, London, 53-62.

[21] Ivert, A.-K., Svensson, R., Adler, H., Levander, S., Rydelius, P.-A. and Levander, M.T. (2011) Pathways to Child and Adolescent Psychiatric Clinics: A Multilevel Study of the Significance of Ethnicity and Neighbourhood Social Characteristics on Source of Referral. BMC Child and Adolescent Psychiatry and Mental Health, 5, 6. https://doi.org/10.1186/1753-2000-5-6

[22] MacFarlane, J.M. (1938) Studies in Child Guidance: I. Methodology of Data Collection and 
Organization. In: Bauer, P.J., Ed., Monographs of the Society of Research in Child Development, Vol. 3, Wiley, Hoboken. https://doi.org/10.2307/1165464

[23] Cohen, J. (1988) Statistical Power Analysis for the Behavioral Sciences. 2nd Edition, Lawrence Earlbaum Associates, Routledge, Hillsdale.

[24] Janson, C.-G. (1984) Project Metropolitan: A Presentation and Progress Report. Department of Sociology, Stockholm University, Stockholm.

[25] Polier, G.G., Vloet, T.D., Herpertz-Dahlmann, B., Laurens, K.R. and Hodgins, S. (2012) Comorbidity of Conduct Disorder Symptoms and Internalizing Problems in Children: Investigating a Community and a Clinical Sample. European Journal of Child and Adolescent Psychiatry, 21, 31-38. https://doi.org/10.1007/s00787-011-0229-6

[26] Robins, L.N. (1966) Deviant Chidren Grown Up-A Sociological and Psychiatric Study of Sociopathic Personality. The Williams \& Wilkins Company, Baltimore.

[27] Kjelsberg, E. and Dahl, A.A. (1999) A Long-Term Follow-Up Study of Adolescent Psychiatric In-Patients. Part II. Predictors of Delinquency. Acta Psychiatrica Scandinavica, 99, 237 242. https://doi.org/10.1111/j.1600-0447.1999.tb07218.x

[28] Silva, T.C., Vitaro, F., Trembley, R.E. and Hodgins, S. (2012) The Association between Maltreatment in Childhood and Criminal Convictions to Age 24: A Prospective Study of a Community Sample of Males from Disadvantaged Neighbourhoods. European Journal of Child and Adolescent Psychiatry, 21, 403-413. https://doi.org/10.1007/s00787-012-0281-x

[29] Nylander, I.A. (1979) 20-Year Prospective Follow-Up Study of 2164 Cases at the Child Guidance Clinics in Stockholm. Acta Paediatrica Scandinavica. Supplement, 276, 1-45.

[30] Kjelsberg, E. (2005) Conduct Disordered Adolescents Hospitalised 1963-1990. Secular Trends in Criminal Activity. European Journal of Child and Adolescent Psychiatry, 14, 191-199. https://doi.org/10.1007/s00787-005-0444-0

Submit or recommend next manuscript to SCIRP and we will provide best service for you:

Accepting pre-submission inquiries through Email, Facebook, LinkedIn, Twitter, etc. A wide selection of journals (inclusive of 9 subjects, more than 200 journals)

Providing 24-hour high-quality service

User-friendly online submission system

Fair and swift peer-review system

Efficient typesetting and proofreading procedure

Display of the result of downloads and visits, as well as the number of cited articles

Maximum dissemination of your research work

Submit your manuscript at: http://papersubmission.scirp.org/

Or contact ojmp@scirp.org 